\title{
Buñuelos de viento
}

\author{
Wind frietters
}

\section{Norma Gómez García ${ }^{a}$, Ana Karen Vargas Muñoz ${ }^{b}$}

\begin{abstract}
:
Fritters are a preparation made of a liquid dough fried in boiling oil. They could be served as snack, appetizer or dessert. They could be sprinkled with sugar or cover them with a light honey, being the most traditional the one made of piloncillo, a type of burned sugar molded as a cone.

For Castellano in her book called "Delicias de Antaño" told us that the nuns of Our Lord of the Snow of St. Brigidag in the year of 1744 they already make the fritters we know actually for the December Festivities. At afternoon nuns used to go out with big trays and seld them, accompanying them with piloncillo honey they elaborated in copper saucepans.
\end{abstract}

Nowadays, some cloisters keep the tradition of making fritters at December Holidays.

Fritters are part of most of the country states cuisine, in some of them they present varieties like in Veracruz, they use to prepare them with crab pulp.

At Oaxaca state fritters are very traditionals at a festivitie called "Radish Night" wich is celebrated at 23rd.December. In each celebration fritters are made with radish, sweet potatoe and potatoe, amongst other ingredients and usually companied with regional atole, wich is a hot beverage maid of corn and flavor. Cocoa maize atole is the most common among them all in the region.

\section{Keywords:}

Fritters, dough, honey, piloncillo, sugar, parties, December, nuns

\section{Resumen:}

Los buñuelos son una preparación a base de una masa liquida y se fríen en aceite caliente; se puede servir como entremés, entrada o postre. Pueden espolvorearse en azúcar o bañarlos con alguna miel, siendo la más tradicional la elaborada a base de piloncillo.

Para Castelló, en su libro "Delicias de Antaño", que las monjas del convento de Nuestra Señora de las Nieves de Santa Brígida, en el año de 1744 ya elaboraban los buñuelos que conocemos actualmente para las fiestas de diciembre. Por las tardes las monjas solían salir con grandes charolas a venderlos, los acompañaban con miel de piloncillo que elaboraban en cazos de cobre.

Actualmente diversos conventos continúan con la tradición de preparar buñuelos en la temporada navideña.

Los buñuelos forman parte de la gastronomía de la mayoría de los estados del país, en algunos presentan diferentes variantes como en Veracruz, que suelen prepararlos con jaiba.

En el estado de Oaxaca son muy tradiciones en la fiesta de la Noche de los Rábanos que se lleva a cabo el día 23 de diciembre; en la fiesta se elaboran buñuelos de rábanos, camote, papa, entre otros ingredientes y suelen ser acompañados con atoles de la región como el de maíz de cacao entre otros.

\section{Palabras Clave:}

Buñuelos, masa, miel, piloncillo, azúcar, fiestas, diciembre, monjas

\footnotetext{
a Profesor de asignatura Área Académica de Gastronomía, Universidad Autónoma del Estado de Hidalgo, Instituto de Ciencias Económico Administrativas, Email: norma_gomez@uaeh.edu.mx.

b Profesor de asignatura Área Académica de Gastronomía, Universidad Autónoma del Estado de Hidalgo, Instituto de Ciencias Económico 


\section{Introducción}

Existe un proceso de homogenización en los patrones de consumo, ya que se encuentran determinados por la zona en donde una familia habita y por las costumbres que existen en cada región. La principal diferencia se asocia al carácter urbano y rural de las localidades. Algunas regiones están más urbanizadas que otras, Sin embargo, encontramos postres tradicionales que se consumían en África y España, como son los buñuelos que adoptaron sabores y olores distintos que lo han convertido en un platillo representativo de las fiestas decembrinas o de otras festividades dependiendo de la región podemos encontrar variedades como: espolvoreado con azúcar y canela o acompañado de jaleas de guayaba, tejocote o naranja.

\section{Elaboración de buñuelos de viento}

\section{IMPLEMENTOS A UTILIZAR}

- Batidor globo

- Tazón

- Taza

- Olla

- Cuchara

- Molde de buñuelo de viento

INSUMOS REQUERIDOS PARA SU PREPARACIÓN

\begin{tabular}{|c|c|c|}
\hline Ingredientes & Cantidad & Unidad \\
\hline Harina de Trigo & 1 & Taza \\
\hline Sal & $1 / 2$ & Cucharada \\
\hline Vainilla & 1 & Cucharada \\
\hline Aceite & 2 & Cucharada \\
\hline Azúcar & 1 & Cucharada \\
\hline Huevos & 2 & Pieza \\
\hline Leche & 1 & Taza \\
\hline Aceite para freír & 1 & Taza \\
\hline Azúcar para espolvorear & 0.100 & $\mathrm{Kg}$ \\
\hline Miel de guayaba & & \\
\hline Piloncillo & 0.250 & $\mathrm{Kg}$ \\
\hline Canela & 0.020 & $\mathrm{Kg}$ \\
\hline Anís estrella & 2 & Pieza \\
\hline
\end{tabular}

\begin{tabular}{|c|c|c|}
\hline Clavo & 3 & Pieza \\
\hline Guayabas & 3 & Pieza \\
\hline Agua & 1 & Taza \\
\hline
\end{tabular}

\section{PROCEDIMIENTO}

\section{Miel de guayaba}

1.- Colocar en una olla el piloncillo con el agua y calentar hasta que se deshaga el piloncillo.

2.- Cortar las guayabas en trozos medianos.

3.- Agregar la canela, anís estrella, clavo y las guayabas.

4.- Dejar hervir por 5 minutos y dejar enfriar.

\section{Buñuelos}

1.- Colocar la harina con la sal y azúcar.

2.- Agregar la vainilla y los huevos uno a uno e integrar.

3.- Agregar la leche y mezclar perfectamente hasta deshacer todos los grumos.

4.- La mezcla queda ligera. Si no está así agregar un poco más de leche.

5.- Calentar el aceite.

6.- Curar el molde de buñuelo en el aceite. Curar se refiere a la acción de sellar todos los poros del molde para que la mezcla no se impregne y quede una capa de teflón.

7.- Sumergir el molde a la mitad en la mezcla.

8.- Sumergir en el aceite y girar para que el buñuelo se desprenda y dorar por ambos lados.

9.- Escurrir el exceso de aceite.

10.- Espolvorear con el azúcar.

\section{Referencias}

Grupo Editorial Larousse. (2014) "Larousse Gastronomique” 1a edicion en espñol 2011.

Catella,.T. (2010) “Delicias de Antaño" Editorial Planeta. 